\title{
The Near-Death Experience in Children: \\ Shades of the Prison-House Reopening
}

\author{
Nancy Evans Bush \\ International Association for Near-Death Studies \\ Storrs, Connecticut
}

But trailing clouds of glory do we come

from God, who is our home:

Heaven lies about us in our infancy!

Shades of the prison-house begin to close

Upon the growing boy.

(William Wordsworth, Ode: Intimations

of Immortality, 11. 64-68)

\begin{abstract}
Some critics have argued that the near-death experience (NDE) is merely a culturally conditioned response to a life crisis, a reflection of expectations engendered by education, religious training, social mores, and family traditions. A review of seventeen accounts of NDEs in children, including two youngsters still in childhood, indicates that NDEs that occur at early ages appear to be substantially similar in content to adult experiences. These accounts suggest that cultural conditioning is not a primary determinant of NDE contents.
\end{abstract}

\section{INTRODUCTION}

Although the occurrence of near-death experiences (NDEs) in adults is now widely accepted as a legitimate phenomenon, evidence of such experiences happening to children has been sparse. Accounts of childhood NDEs in the archives of the International Association for Near-Death Studies (IANDS) are primarily retrospective, written as many as sixty-five years after the event. Though these accounts are often vivid, they are necessarily filtered through an adult consciousness. Melvin Morse (1983) has recently described an NDE occurring in a seven-year-old child, and Glen Gabbard and Stuart Twemlow (in press) have discussed details and implications of NDEs in three children between the ages of five and seven. A study of

Anabiosis - The Journal for Near-Death

Studies, December 1983, Vol. 3, No. 2 
contemporary childhood experiences is currently underway at the University of Connecticut School of Nursing, which may ultimately provide fuller information about this aspect of near-death research.

Recently IANDS received letters from two mothers of children who had had NDEs during near-drownings. We present in this paper details from our contacts with these two mothers, and elements of fifteen retrospective accounts of childhood NDEs from the IANDS archives. In the absence of more abundant data from a larger sample, this article offers no interpretation of these experiences. Premature speculation as to their psychodynamic or developmental import for child experiencers might serve only to muddy waters now being explored for the first time. For now, the experiences described here will serve as introduction.

At least in the United States, from which these experiences came, adulthood may be characterized as the time when a person may legally be employed, marry, and drive. In most states, these activities become legal at age sixteen, making this age a convenient measure for defining the onset of adulthood. Experiences occurring above the age of fifteen have been excluded from this survey.

\section{RETROSPECTIVE ACCOUNTS}

Of the available retrospective accounts, fifteen are sufficiently detailed to provide a clear picture of the experiences. Fourteen of these have been remembered clearly since the event - a period ranging from 11 to 65 years. The other, occurring at the age of 13 months, was recalled 27 years later under hypnosis.

Causal events were, in most cases, relatively common childhood disasters, at least at the time of occurrence: there are four neardrownings; three ruptured appendices; two unidentified illnesses with prolonged high fever; and one case each resulting from mastoiditis, pneumonia/mastoiditis, drug allergy, and a fall. Of two incidents not typically childhood-associated, one resulted from a "heart attack" (no other information given) and one when a boy was swept into a flood-swollen river (not a near-drowning). There is no correlation between age and precipitating event.

These retrospective experiences are here categorized by their predominant NDE features, ordered by frequency of mention rather than by sequence within the experience(s). 


\section{The Light}

The adults interviewed for Kenneth Ring's Life at Death (1980) were asked, "Did you at any time experience a light, glow, or illumination?" Thirty-four percent answered affirmatively. In Michael Sabom's study (1982), light appeared as a prominent feature in 28 percent of the responses. In the current survey's unsolicited retrospective accounts, with no question asked that might prompt a mention, light is the single most-noted feature of the NDEs, appearing in 65 percent of the experiences.

A nine-year-old girl had a near-death experience four hours after surgery for a ruptured appendix, her surgeon having already told her parents that she would probably not live through the night. As she described her NDE,

[Then] the blackness was gone and in its place was a beautiful soft pink light. All the weight was gone, and I floated back up into the room as light as a feather. I seemed to be filled with this same light, which was the most profound spirit of love that you can imagine. Nothing has ever come near it since. I opened my eyes, and the whole room was just bathed in that beautiful light. In fact, the light completely surrounded everything in the room, there were no shadows. I felt so happy .... I heard my father say, 'What's she looking at?' The light lasted for a little while and it was wonderful.

Another nine-year-old girl, diving off the high board at summer camp, slipped and plunged uncontrolled into the ocean. Underwater for ten minutes, she later reported:

The next thing I remember is floating only an inch or two from the ocean's sandy bottom in the midst of a great light. The light wasn't the bright glaring sort of light that makes you blink. Instead, this light was incandescent, almost ethereal. I could see every indentation and curvature in the sand and minute details in the seaweed. If there were fish or shells, I don't remember them. I felt absolutely nothing. Not the water, nor the sand, nothing. I was surrounded by silence, but I wasn't afraid. I wanted to stay there forever. I have never since experienced such a feeling of peace.

A four-year-old girl descended the cellar stairs with a flashlight because the bulb at the landing had burned out. Years later, she reported:

As I started to take the first step down, I flashed the beam of light up at the light bulb, curious to see if a burned-out bulb looked "burned." I stepped out and fell into the darkness.

The next thing I was aware of, was being up near the ceiling over the foot of the stairs. The light was dim and at first I saw nothing unusual. Then I saw myself lying, face down, on the cement, over to the side of the stairway. I was a little surprised, but not at all upset at seeing myself 
that way. I watched and saw that I didn't move at all. After a while, I said to myself, "I guess I'm dead." But I felt good! Better than I ever had. I realized I probably wouldn't be going back to my mother, but I wasn't afraid at all ...

I noticed the dim light growing slowly brighter. The source of light was not in the basement, but far behind and slightly above me. I looked over my shoulder into the most beautiful light imaginable. It seemed to be at the end of a long tunnel which was gradually getting brighter and brighter as more and more of the light entered it. It was yellow-white and brilliant, but not painful to look at even directly. As I turned to face the light with my full "body," I felt happier than I ever had before or have since.

Then the light was gone. I felt groggy and sick, with a terrible headache. I only wanted my mother, and to stop my head from hurting.

A fourteen-year-old boy and his family, trying to escape from their car trapped on a bridge by rising flood waters, were swept over the side and downstream. He later wrote to IANDS:

I knew I was either dead or going to die. But then something happened. It was so immense, so powerful, that I gave up on my life to see what it was. I wanted to venture into this experience which started as a drifting into what I could only describe as a long, rectangular tunnel of light. But it wasn't just light, it was a protective passage of energy with an intense brightness at the end which I wanted to look into, to touch.

... As I reached the source of the light, I could see in. I cannot begin to describe in human terms the feelings I had over what I saw. It was a giant infinite world of calm, and love, and energy, and beauty. It was as though human life was unimportant compared to this. And yet it urged the importance of life at the same time it solicited death as a means to a different and better life. It was all being, all beauty, all meaning for all existence. It was all the energy of the Universe forever in one place.

As I reached my right hand into it, feelings of exhilirating anticipation overwhelmed me. I did not need my body any more. I wanted to leave it behind, if I hadn't already, and go to my God in this new world.

\section{A Sense of Well-Being}

Of Ring's (1980) adult sample, 20 percent identified having experienced a sense of well-being ("happy," "good," "beautiful"), with 60 percent remarking on the feeling of peace. Among the retrospective childhood accounts, the percentages are almost exactly reversed - 53 percent reporting the sense of well-being and 35 percent feelings of peace. For the two groups, then, 80 percent of the adult experiences and 88 percent of the childhood NDEs included well-being/peace.

As a developmental issue, it will be interesting to see whether larger samples of children reporting recent NDEs follow the pattern of mentioning having felt "happy" and "good" rather than "peace." 
A thirteen-month-old girl, hospitalized with pneumonia in both lungs and mastoiditis in both ears, was too sick to tolerate surgery. Considered near death, she later relived the experience under hypnosis:

I am strapped down - hands, legs, body. I feel excruciating pain. There [are] big people all around [with] enormous hands... All at once I am safe. I am being rocked to sleep in a soft, warm and utterly serene and secure cradle. There is no pain, no noise, no turmoil - only peace, beautiful peace. The overhead light in the room is gone; in its place is all-encompassing light, the light which communicates safety and love. I feel so warm and confident inside. There is no pain. I can breathe easily; my limbs are free to move and $I$ am all safe. . . . My eyes fix on the window across the room; it is outlined with the warm and happy light. My mother is looking through the window at me.

A thirteen-year-old boy who nearly drowned later reported:

It was a feeling of no pain at all. Like a floating feeling. It was like a beautiful rest period. If I was near death, it was beautiful.

A fourteen-year-old girl with an abscessed tooth had an allergic reaction to sodium pentathol that she was given. Years later, she wrote:

I was traveling towards [the light] rather quickly. I was very warm and cozy and knew something wonderful was at the end of the tunnel and in the light.

A fourteen-year-old girl with a ruptured appendix later reported:

I did not hurt any more. I was surrounded by a puffy cloud. I really was floating in peace. I have never felt as good. My parents asked me if I needed to go to the hospital. I told them no, because I didn't hurt any more and I was dying.

\section{Out-of-Body Experiences}

Ring's (1980) adult sample included 37 percent reporting outof-body experiences, with roughly 33 percent identified as "visually clear." Among the retrospectively reported NDEs surveyed here, a total of 47 percent reported feeling separated from the physical body, 41 percent of them visually clear experiences.

An eight-year-old boy whose ears had just been lanced for mastoiditis later reported:

Mother was covering me when I felt I was rising up in the air. Although I could see I was rising toward a bright light, I could_also look down and see Mother kneeling beside me....

A twelve-year-old girl was rushed to the hospital with a ruptured appendix. She later wrote IANDS: 
I became aware that not only was I completely out of pain, but that I seemed to be somehow floating along, above the ambulance. I could see my still, white form lying on the stretcher, my mother with tears in her eyes, leaning over my body, my father in the car behind the ambulance, white knuckles grasping the steering wheel. In addition, I could see my grandmother pacing up and down our living room, about fifteen miles in one direction, and my [physician] uncle at the hospital, fifteen miles in the other direction. At the time, nothing seemed odd about being able to be with all of those people at the same time. I remember feeling very detached from them, much as I feel if I walk down a strange street and casually glance into someone's back yard.

A six-year-old boy with polio fell face-down in foot-deep water in which he was wading without his leg brace. Years later, he wrote:

Suddenly I was viewing the scene from a vantage point about two or three feet above, behind, and to the right of my mother's right shoulder. She was sitting on the beach in a folding chair. My next older brother was playing in the sand to her right, and I could see myself floundering in the water between and beyond them. Just as I got there, my mother put down the newspaper she was holding open in front of her and reading, saw me in the water trying to call for help, and then turned to my brother and calmly told him, "Go pull your brother out of the water." I remember the words distinctly. I saw my brother stand up, walk out into the water where I was, and reach down and grab me by the shoulder. The next thing I knew, I was back in the water with my brother pulling me up.

\section{The Tunnel, Darkness}

Once again, the childhood retrospective accounts show a higher percentage of mentions of entering darkness or "the tunnel" than adult accounts. The adults surveyed by Ring (1980) reported a 23 percent incidence of "entering the darkness" (41 percent in the retrospective accounts), with an 18 percent incidence of the tunnel (30 percent in the retrospective accounts).

A ten-year-old boy, sick for several weeks with an unidentified illness, had an NDE shortly after "the doctors had given up":

... I don't remember the entrance, but in a little while I was in a dark tunnel. There was absolutely no sound, and all was black. I couldn't see to make my way through the tunnel, but I was being wafted along as a speck of dust, pitch black, but as I went along with neither sight nor sound, I felt at ease. I thought I was discovering a new cave.

After a while the tunnel became square in section, and along I went and I became annoyed, and thought to myself that the journey was pointless and fruitless and I was wasting valuable time. Just when I was about to turn back in disgust (I was completely alone), I saw a tiny speck of light ahead. I went on, and as I did the speck grew larger, and I thought it was well I hadn't turned back because I was going to discover something at last. 
At about 150 yards from the end, I saw plainly that there was brilliant white light out there beyond the square end of the tunnel. It interested me and I went on. All was yet quiet, and I went blissfully on, enjoying the journey at last.

When I was about twenty-five yards from the end, the light became the most brilliant I have ever seen, yet it did not hurt my eyes. I began to wonder about that light because all I could see was light: no landscape, no people, nothing but a sea of light. And not a single ray entered the tunnel. The tunnel was black right to the end, and then there was the sea of light.

I went closer, cautious now because it seemed that the end of the tunnel was pretty high up on the side of a cliff, and since I couldn't see through the light, I didn't know how far the drop might be, if 1 left the tunnel. When I was near the end, I took a good look around at the sea of light. I was urged to jump into it, and assured that I would not fall to ground. No voice said this, it just came to me from a kind of presence. I thought it might be fun to try; but in an instant I knew that if I left the end of the tunnel I'd never find it again, and hence never get back home.

I turned around and started back through the tunnel, and that is the last I remember.

[The final paragraph of this account reads, "Believe me, if you go through what I have described, you come back with the thought that it's a good thing you didn't dive into that whipped cream of lovely light too soon. But you know you have 'seen the light."']

A post-operative nine-year-old girl, the first case described above, reported:

Then a strange uneasiness came over me, and as I watched, the darkness from the hall gradually came into the room and filled it. It seemed to have a weight to it, and as the room got darker, it became harder for me to breathe, like there was a weight on my chest. It felt as if this darkness was pushing me down, and as I looked up at the ceiling I noticed that it was getting smaller and smaller. It was like being pushed slowly down a mine shaft.

A fourteen-year-old girl with an allergic reaction to sodium pentothal, described above in the section on "Well-Being," also reported:

All I knew was I was traveling - not walking or running, just somehow moving smoothly - down a long black tunnel with bright green and red lights on either side. At the end of the tunnel was a yellow or golden light. I was traveling towards it rather quickly.... It seems I got about half-way to the light when I started to reverse and it got colder. The next thing I knew ... the dentist said, "You gave us quite a scare."

The fourteen-year-old boy swept over the bridge, also described above, stated:

This experience ... started as a drifting into what I could only describe as a long rectangular tunnel of light. But it wasn't just light, it was a pro- 
tective passage of energy with an intense brightness at the end which I wanted to look into, to touch.

\section{CONTEMPORARY ACCOUNTS}

The near-death experiences recounted here occurred between the ages of 13 months and 14 years; they were written down by the nowadult experiencers anywhere from 11 to 65 years later. Median age of the adults at the time of writing was 48 , with a range of 25 to 72 years.

Specific analysis of the differences between retrospective accounts and those of children remembering recent experiences will obviously provide useful information; however, that study must wait for the accumulation of an adequate population of recent child experiencers. The two accounts that follow are more recent, as the experiencers are still children. Both are direct transcriptions of the child's experience as told to the mother. Although it would be highly desirable to have a tape of the child describing the NDE himself, this lack may be counter-balanced by the fact that in relating the account to his mother, the child was in a natural setting in which he was, quite literally, "at home," and without the need to adjust to an unfamiliar interviewer.

\section{Robin}

Because of its remarkable force and openness, Robin's mother's letter is reprinted here almost in entirety.

On December 18, 1971, I had my son. My husband Jose and I were overjoyed. A beautiful perfect strong son. He would kick so hard in the bathtub I would be frightened of his strength. A beautiful boy. So good. He never cried much. He smiled so early. Never sick. So strong.

The morning of August 9,1975, my husband was very nervous all morning. He was to meet my sister, husband, and two children for the first time. He agreed on that, but all the way up to our family home, Jose would say, "I don't want to go to [Crystal] Lake." [But] we all went. ...

We got on a boat to go out to our own private area. . . Robin cried all the way on the boat across the lake. I remember the heat was very intense. Dry, too. When we arrived, I can remember pulling him with all my strength off the boat. Jose came over to me and said, "I hate it here." I had Robin in my hand and he was still angry. I let go of his hand and told him, "Robin, Mommy is going to get you an inner tube," but he said, "No." I turned around and he was gone.

I looked around and everyone was swimming or sunbathing. My sister Beth had already put her blanket down and was laying down sunbathing. She had two boys with us, one Robin's age. The men were already swimming. I let out a scream of death. "Beth, I can't find Robin!" 
Within seconds, everyone on the beach was looking. Ten minutes went by. No Robin. I ran up on a hill. Jose followed. The rocks on the hill felt like razors on my feet but I didn't care. I hoped Robin went up the hill. Jose embraced me. I felt totally helpless as I screamed in his arms and he cried in mine. I just knew he was dead.

As we looked down the hill, a lifeguard boat drove up. Everyone screaming to have him help. Jose left me and went back down to look. Three lifeguards. About fifteen men by this time.

As I started down the hill, Robin came up feet first by the lifeguards. Fifteen minutes in ten feet of water by the dock. No one knew the dock was deep because the lake about two feet away was shallow. A new lake and no signs. By this time, sheriffs were holding me away from Robin. Jose was holding me, too. I remember feeling worthless because I couldn't get to my own son. I prayed. My sister left a second and came running back. "He is alive, they have a heartbeat."

I said, "No, she is saying that so I won't go crazy." When I saw a helicopter, I then felt maybe, because they wanted to take him to the hospital nearby.

[At the hospital] we met a lady doctor. She told us, "He's alive, but very, very sick." She stayed with Robin for many hours. Robin was in a deep coma. Machines and a plastic box over his head. I couldn't touch him. My baby, three years and eight months. Our tears were endless.

The doctor transferred him to [the] Medical Center and stayed with him all night until he was stabilized. I drove out [there] three times a day because my work wouldn't let me off. We tore our car apart, but I didn't care.

Two weeks. No change. One day I went in his room. His bed was stripped. No sheets, no Robin. I dug my fingers into Jose. A housekeeper came in his room and said, "He's down the hall." We walked down the hall, always numb. I thought he was dead. As we slowly walked into the room, Robin was laughing at a clown passing out balloons.

The next day he was in a wheelchair. We took him down to the cafeteria for lunch. He ate like a horse. Talking to us. Walking with us slowly for a few days.

In three weeks he was back to the day-care center.

No brain damage. Just ear damage that has been corrected.

Robin is eleven now, and about six months ago he shared something with me about the white light. I couldn't understand until I listened carefully.

... He said, "A long time ago I was awake. Not asleep! I was going up in the air and saw you and Papa crying. Something came to me and said you have to go back. I felt good [to come back], but I liked all the people I saw."

I asked Robin who he saw, and he said they were too bright, but, "One man held me and I felt so good I wanted to stay, but he said no."

Just a few days ago, I reminded Robin of what he told me and he didn't remember and laughed at me. Maybe someday he will remember again.

I do know God gave me back my son, but I know he is not mine forever. $\mathrm{He}$ is a gift I must take good care of until he is ready to share his life with others. 
Jer was four when he fell into the deep end of the apartment house swimming pool. A year later, his mother heard of IANDS and wrote, saying, "I need help in trying to explain certain things which I know nothing about. Don't think this is a crack-pot letter. I'm really confused about this."

What follows is a verbatim account (rearranged for chronological sequence) of a lengthy telephone conversation with Jer's mother.

The day it happened, Jer had gone outside to play. Maybe ten minutes. I had checked on him maybe ten minutes before. The other boys came running and told me Jer was in the water.

My girl friend pulled him out of the pool. I knew he was dead. I could see it on his face. His lips were pale blue. I knew he was dead. I started mouth-to-mouth, and then my other girl friend took over. He was in the water four or five minutes, in the deep end. The paramedics got there real quick.

The day of the accident, two doctors had come from [the Medical Center] to do a conference on the new controlled coma procedures for drownings. They were still at our little hospital and they drove back to [ the Medical Center] with Jer. They started him on the drugs right away.

They put him into a controlled coma for seven days, with his temperature way down. The first brain scan they did was unreadable. They said there was just nothing there.

I knew if I was there with him in the hospital he'd be okay. I knew it, in spite of what the doctors said. They said there would be severe brain damage, and we'd better be preparing ourselves for it.

We drove to [the Medical Center] every morning, a $1 \frac{1 / 2}{2}$ hour trip each way. I'd go in and say, "Hi, Jer, Mom's here," and I'd kiss him. And his heart rate would go up. Some of the doctors said we didn't have to be there, that it was too much for us every day, but I knew we had to be there. I know he knew somehow that we were there. They told us to keep talking to him. His heart rate went up, and other things.

Two or three days later, they did another brain scan. The nurse said it was better, but the doctors still said there was major brain damage. They said he might die when they started to warm him up. They started warming him up on Thursday. They said it might take until Sunday, because they were doing it real slow, but he started coming around almost immediately. They didn't know what to do, he was coming around so fast.

They said he wouldn't remember anything about the experience, if he could remember anything at all. They really expected him to be so damaged. But when he woke up, the first thing he said was, "Get me a doctor I'm drowning."

I should tell you, Jer has always been terrified of water. He was just terrified. After we got him home from the hospital, we had a little party for him. Kind of a welcome back. I mean, we were just so glad that he was - well, that he was back at all. And the first thing he did, he said he wanted to go in the pool. I nearly died. I never wanted to go near the thing 
again. But I put his floaters on him and he went over and dove right in the deep part. When he came up, he said to his brother, "See, Jon, I came back again."

He walked around with this for almost a year, and then one day he came to me and said, "Sit down. I have to talk to you, Mother." That's not a five-year-old. He never calls me "Mother."

He said, "When I drowned, I didn't want to come back. I saw something real pretty in the sky. I saw you and Josie and another lady working on me. I was sitting on the roof and I could see you.

"Then it got real dark and I walked down a tunnel. There was a bright light at the end, and a man was standing there."

I asked him, "Who was the man?"

He said, "It was God. And I said I wanted to stay. But God said it wasn't my time yet and I had to come back. I put my hand out and God put his hand out and then God pulled his hand back. He didn't want me to stay.

"On the way back, I saw the devil. He said if I did what he wanted, I could have any thing I want."

I said, "You know God is good and the devil is evil."

He said, "The devil said I could have anything I wanted, but I didn't want him bossing me around."

I said, "Mom and Dad wanted you back real bad, and God knew that. He let you come back to us." And he said, "When I fell in the water, I called and called for you, but you didn't hear me."

Since his experience, Jer's mother reports, he has become moody, with dreams - good and bad - that affect his behavior the following day. She says he gets "a faraway look" and says his dreams are sometimes about "castles in the sky."

The beginning of school led to severe behavioral disruptions that have led Jer's parents to take him for counseling. Believing the neardrowning experience to be related to the behavior changes, Jer's mother told the psychologist about it; however, the response was, "You know children and their imaginations." The therapist will not discuss it.

Our interview concluded with the following:

When he gets moody, I'll ask him why.

"I think I'll keep that my business for a while," he says. It's like a grown-up person in a little body. He seems to have no sense of fear, and that scares me. Pain doesn't seem to bug him, either. It just doesn't bother him.

He gets this faraway look and if I ask he says it's so nice there. Is he going to try to do something to get back there? I think there's something there, too, that he doesn't want to talk to Mom about. Something is bothering him that he can't tell me. What do I do? I mean, I'm saying, "Come on back, Jer," and God's up there, and I'm saying - what do I do now? 


\section{FEATURES OF CHILDHOOD EXPERIENCES}

Adherents to the "tabula rasa" view of childhood development may find these accounts disquieting. There is no indication here that children's experiences are simpler, less detailed, or different in structure from those occurring in adults as described by Raymond Moody (1975), Ring (1980), Sabom (1982), and George Gallup (1982). What may be most remarkable about them is that, when compared with the content of adult experiences, they are so unremarkable.

Quantitatively, differences in the rates of occurrence of specific features are obvious, using Ring's (1980) data for comparison. However, as Ring's respondents participated in a structured interview and the childhood experiencers did not, the comparability of the percentages may not be reliable. With this qualification, the percentages are given in the Table on page 189.

\section{Child/Adult Experience Comparisons}

The incidence of certain features in these childhood NDEs varies from those of adult experiences.

Life review and judgment. Both Moody (1975) and Ring (1980) found a strong relationship between the life review and the idea of judgment. It is all the more interesting, then, that none of the childhood accounts includes a life review, for nowhere in any of these experiences is the word "judgment" mentioned, nor "judge," nor the idea that one's life might be evaluated as "good" or "bad." The concept is totally absent, even among the older children who might have been expected to identify more closely with adult thought patterns, and in the three who believed themselves either dead or dying.

Four of the children encountered a figure or presence, variously identified as "God," "a big man," or "like a giant." Although the ages of the four are three years and eight months, four, nine, and fourteen years - obviously representing widely differing developmental stages - the concept of judgment or of "goodness/badness" is absent from them all. Fear is not mentioned as an element in the encounters, nor are awe, joy, bliss, nor any of the other characteristics described by adults. One could call this group of children matterof-fact in encountering the presence.

Encounters with deceased persons. It is probably not surprising that only two of these childhood accounts report meetings with 


\section{PERCENTAGES OF NEAR-DEATH EXPERIENCERS REPORTING NDE FEATURES}

Feature

Light

Sense of well-being (happy, good, beautiful)

Separation from body Autoscopic OBE Entering the darkness

Tunnel

Peace

Absence of fear

Encounter with spiritual presences, voices

No pain

Floating

Silence

Wisdom, "knowingness"

Ineffability

Negative elements

Landscape

Encounter with deceased people

Sense of dying

Sense of a boundary

Believed self dead

Life review

Chose to return

Told to return

"Just came back"

No information about return
Incidence

Childhood N=17 Adult N=49

(Unsolicited mentions)

$65 \%$

$53 \%$

(Solicited

mentions)

$34 \%$

$20 \%$

$47 \%$

$41 \%$

$41 \%$

$37 \%$

$30 \%$

$35 \%$

$35 \%$

$35 \%$

$23 \%$

$18 \%$

$60 \%$

$47 \%$

$40 \%$

$24 \%$

$24 \%$

$24 \%$

$24 \%$

$18 \%$

$18 \%$

$18 \%$

$12 \%$

$49 \%$

$12 \%$

$6 \%$

$6 \%$

$16 \%$

$-$

$49 \%$

$-$

$20 \%$

$16 \%$

$39 \%$

$27 \%$

$25 \%$

$0 \%$

$25 \%$

$12 \%$

$34 \%$

$24 \%$

$23 \%$

$30 \%$

$35 \%$

$57 \%$ 
deceased persons. One, a twelve-year-old, said he met "a teacher and a schoolmate"; the other, an eight-year-old boy, reported entering a garden and meeting a girl somewhat older than he who identified herself as his sister. Asking his parents about her later, he discovered that an older sister had died at birth.

Knowing; the feeling of wisdom. Although adults have reported a powerful sense of knowledge, of being suffused with information that sometimes - and startlingly - surfaces after resuscitation, the children's experiences tend to be presented in specifically age-related terms. "The overwhelming feeling was one of wisdom or a great 'knowingness,"' wrote a woman of her experience. "That is a strange feeling for a twelve-year-old who one moment has the sense that all grownups know so much and then the next moment feels so wise. I recall sort of pausing to savor that feeling."

Another wrote, "I felt wonderful and calm and strong. I wasn't nine years old, I was eternal."

And about an experience at the age of four, a woman noted, "I felt strong and confident, with a strong sense that everything was all right. I didn't feel like a little child or any age at all."

Absence of fear. Although mentioned more frequently by adults (47 percent as compared to 35 percent in children), absence of fear appears as a strong element in the six accounts in which it is explicit. In all cases, the lack of fear is especially noted for its contrast to the child's usual feelings; its absence is marked, specific, and clearly remembered. In their accustomed selves, said the writers, they were timid, afraid of heights, fearful of separation from their parents, frightened in strange situations, or aware of being powerlessly small; yet during the NDE, these terrors vanished.

By contrast, adult comments about being unafraid are stylistically more casual, on the order of an offhand remark. Reading a group of the childhood experiences, by contrast, evokes powerful reminiscences of the nameless terrors that accompany being very young.

Worth mentioning for its fearless tone is the account of the tenyear-old boy exploring the "pitch black" square tunnel. "I thought I was discovering a new cave," said the writer, and then, ". . I was wasting valuable time. Just when I was about to turn back in disgust ... I saw a tiny speck of light ahead. ... I thought it was well I hadn't turned back because I was going to discover something at last." Despite a lapse of forty-five years, the account carries with it a whiff of Huckleberry Finn.

Negative elements. Sabom reported that "Momentary fright or bewilderment sometimes accompanied the initial passage into dark- 
ness. ... In time, however, these unpleasant emotions were replaced with calm, peace, or tranquillity" (1982, p. 41). Ring noted that "Although people sometimes report feeling scared or confused near the beginning of their experience, none felt they either were on their way to hell or that they had 'fallen into' it" (1980, p. 192).

In general, the childhood accounts corroborate these remarks, with some qualifications. One lengthy account describes an experience, not characterized by its writer as "hellish," which was nonetheless very frightening to her right up to a last-minute rescue by a presence. The experience of the four-year-old who said he met "the devil" has not yet been investigated by direct interview with the youngster to elicit his reaction to or interpretation of the incident. His account, as reported by his mother, is unusual not only for its specific mention of "the devil," but also because the pattern of his experience moves from positive (strongly wanting to stay with the presence he identifies as God) to negative (encountering, and not wanting to remain with, a presence identified as negative). This is in contrast to the Ring and Sabom findings that negatively inclined experiences resolve positively.

The tunnel. A curious finding is that the only four-cornered tunnels mentioned in all of IANDS' archives are the two appearing in these accounts, one described as "square in section" and the other as "a long, rectangular tunnel."

Light. As indicated earlier, an average of 31 percent of the Ring and Sabom adult experiencers mentioned light as a prominent characteristic of the NDE, while 65 percent of the childhood experiencers described it as a major feature. In an effort to identify specific differences in the descriptions of child and adult experiencers, I was able to find only one minor variance: in none of the childhood accounts is the light termed "magnetic," although in two instances anticipation is mentioned. Quite possibly because the majority of these accounts are retrospective, vocabulary differences are minimal; descriptions of the light's color(s) and affective elements show no more variance than can be found within a group of all-adult experiences.

In short, in this sample of childhood accounts, the light is described almost exactly as it is in adult narratives, but is mentioned twice as frequently.

\section{CONCLUSION}

Despite the small number and retrospective nature of the available accounts, certain conclusions appear justifiable. 
1. Near-death experiences can and do occur in children, quite possibly even among youngsters in pre-linguistic developmental stages. Data collection from very young experiencers will present interesting, though probably not insurmountable, challenges to researchers.

2. Childhood experiences appear to follow patterns similar to those encountered with adults. With the exception of the life review and sense of judgment (at least in the experiences surveyed here), the features of children's experiences are comparable to those reported by adults in content, affect, and perceived significance, though wide variances have been noted in frequency of certain features.

3. Within the childhood population, age is unrelated to the type or complexity of experience. In an all-child population (as contrasted with the adults writing retrospectively), attained language development may affect the likelihood of capturing complete and accurate descriptions, as may the development of conceptual abilities. In the accounts presented here, it is not possible to determine how much of the affective interpretation is an adult overlay, though the specificity of memory detail in some cases (see "Knowing; the feeling of wisdom" section) suggests that this is not a major issue.

4. According to the writers of these retrospective accounts, the aftereffects of childhood experiences may be subjectively perceived as strongly as those that follow adult experiences. With little "before" and much "after" in the lives of the experiencers, examination of this issue will be muddied as developmental changes mask clear identification of most behavioral aftereffects. However, Jer's experience alone is sufficient testimony to the need for thoughtful study of NDEs in children, with careful attention given to their aftereffects and the development of interventions that will support the children and their families as they work through integration of the experience.

\section{REFERENCES}

Gabbard, G.O., and Twemlow, S.W. With the Eyes of the Mind. New York: Praeger, in press.

Gallup, G., Jr. Adventures in Immortality. New York: McGrawHill, 1982.

Moody, R.A., Jr. Life After Life. Covington, Ga.: Mockingbird, 1975. Morse, M. A near-death experience in a 7-year-old child. American Journal of Diseases of Children, 1983, 137, 959-961.

Ring, K. Life at Death. New York: Coward, McCann and Geoghegan, 1980. 
Sabom, M.B. Recollections of Death. New York: Harper and Row, 1982.

Requests for reprints to:

Nancy Evans Bush

Box U-20

University of Connecticut

Storrs, CT 06268 